\title{
A REVIEW OF PERSON-ORGANIZATIONAL CONGRUENCE AND OUTCOME VARIABLES
}

\author{
Nawaz Ali \\ PhD Research Scholar (SRF), Department of Commerce, University of Kashmir-190006 (India) \\ Dr. Parvez Ahmad Shah \\ Sr.Assistant Professor, Department of Commerce, University of Kashmir-190006 (India)
}

Article DOI: $\underline{\text { https://doi.org/10.36713/epra5102 }}$

\begin{abstract}
The accessible writing is occupied with affirmation proposing the necessity for picking and utilizing proper individuals for the organization's, likewise as reporting the significance of congruence among people at workplaces with the organization and making this relationship among the duo stronger for the general accomplishment of the great number of objectives of the organization and all the stakeholders associated directly or indirectly with the organizations. Likewise, researchers, experts and practitioners in the field of organizational behaviour and its allied fields across the globe have demonstrated and proved a lot of enthusiasm in examining the domain of person-organizational congruence in relation to several individual level organizational level outcomes like, organizational commitment, work satisfaction, organizational citizenship behaviour, work performance, turnover intention and intention to stay. Research's that have been carried out as of now on person-organizational congruence and its relationship with several individual level and organizational level outcomes were limited in context to the Indian settings and growing number of studies advised a need to further investigate person-organizational congruence and its relationship with individual and organizational level outcomes. In light of this developing essentialness associated to the phenomenon of person-organizational congruence domain the present examination is as such a modest undertaking toward this way.
\end{abstract}

KEY WORDS: person-organizational congruence, organizational outcome variables, individual outcome variables

\section{PRESENTATION AND THE SURVEY OF THE LITERATURE}

Organizations' success and sufficiency depends on various factors and it is no exaggerate to argue that the organization's fate lies in the hand of the workers associated with it. Associations should end up being progressively homogenous after some time through interest, assurance, trimming down, and socialization of the people working in that very organization (Schaubroeck 1998). Individuals' who feels that they are congruent to the organization are get attracted into it, and organizations are bound to choose them. those individuals who don't feel that they are not congruent to organization where they work generally leave, on the contrary individuals who are not in congruence with the organization indulges into the procedure of socialization that expands the degree of congruity of the duo. Thus, Schneider (1987) contends that persons acting in an organization are bound to function for the organization, as oppose to the person and environment generating behaviour. Personorganizational congruence meaning emerged and revolves around the matching values of both organization and the persons working in an organization, which is generally known as value 
congruence (O'Reilly, Chatman, and Caldwell, 1991; Chatman, 1989). The notion of person-organizational congruence moreover has been stretched out to fuse interchanges among individuals and their occupations, supervisors and their subordinates, individuals and organizations, within groups despite the principal thought of congruence between the individual and organization. Researchers, practitioners and analysts as such, contends that person-organizational congruence is the best approach for the organizations to maintain a satisfied and committed workforce which is imperative for organizational effectiveness and success in a competitive business environment.

Person-organizational congruence and personorganizational congruence is used interchangeably. The present study has used person-organizational congruence instead of person-organizational congruence. The fundamental of basic research on person-organizational congruence can be traced back to the work of Schneider (1987), wherein he coined the model of Attraction selection and attrition model, and applied the same to the working of an organization. He is of the view that peoples for an organization are not haphazardly relegated to a circumstances, rather they lookout for circumstances that are pleasing to them. Additionally, Schneider contends that organizations are circumstances that individuals are enticed in to, choose to be a piece of, and stay with in the event of a solid match with the organization, or leave in the event of any mismatch with the organization. Additionally, matching the person and the organization (i.e. personorganizational congruence) has been connected to several outcomes of the individual and the organization as well, like, organizational commitment, job satisfaction, turnover intention and job performance (Michelle L Verquer, 2003; Johnson, 2005; J.Woehr, 2006; Wheeler, Gallagher). Generally, the similarity of person and the organization where they work is referred as personorganizational congruence (T. Sekiguchi 2003). Specifically, wherein he argued that personorganizational congruence alludes to the condition of likeness between the values, goals, interest of a person, and the values perceived by the organization. Although, as delineated by existing writing, studies on evaluating the connection of personorganizational congruence with different individual level and organizational level outcome variables (like, employee job satisfaction, organizational citizenship behaviour, employee job performance, employee innovativeness, workplace spirituality and organizational commitment) is as yet not abundant. The idea of the current study is to delve in to the literature of person-organizational congruence in relation to the individual and organizational level outcomes. Thereby, making an in-depth review of the writings associated with the domain of personorganizational congruence in relation to several organizational and individual level outcomes. Writing on outcomes of person-organizational congruence has exhibited noteworthy associations with significant individual outcome variables, for example, employee job satisfaction, employee commitment and employee performance. Getting antecedents and outcomes of similarity among individuals and the organizations where they work has transformed the person-organizational congruence into an area of attention for the analysts, practitioners, and researchers during ongoing years across the globe.

Downey et al., (1975) was one of the first to direct work on person-organizational congruence wherein their findings led them to made a suggestion that workplace atmosphere communicates with personality of an individual in impacting employee job satisfaction and employee work performance by they carried out a study of 92 managers and found that people with requirement of high social contact and reliance with other employees at the workplace, and who see their organizational atmosphere as system of having a reward were best employees of the organization in term of performance when contrasted with low amiable colleagues. Likewise, people with requirement of more social contact and relationship with colleagues at workplace and who see the organizations' atmosphere as open and sympathetic and set elevated requirements for the success were all the more strongly satisfied. (Charles A. O'Reilly III, 1991) for instance, likewise surveyed person-organizational congruence based on value congruence by utilizing information gathered from graduate students, centre-level managers and accountants engaged by a government office, each belonging to a discrete group by designing a profile of organizational culture which is known as organizational culture profile. Their study led them to the findings that employee's notable person-culture level was positively and significantly connected to employee job satisfaction, organizational commitment and employee intention to stay with the organization. Continuing on the same assumptions (Judge, 1992) analyzed the connection of personorganizational congruence in relation to achieved career achievements of employees, and their inclination toward the organizational atmosphere wherein they work. To carry out their investigation they selected graduates of two big universities pursuing industrial relations. The outcomes of the investigation proposed that outward measurements of achievement (like pay, level of work, and promotions granted to them), and inward measure of achievement (like work and life satisfaction) were equally affected significantly by how much that individual is congruent to the organization. Moreover, in this regard (Vanka, 2005) support the viability of personorganizational congruence measures (value congruence, goal workplace environment congruence and personality congruence) in predicting employee 
job satisfaction and employee job performance across culture of management training and education. An aggregate of 194 students of management classes from four segments all of them instructed by educators from United states of America and India's higher education institutes were selected to extract data, outcomes of this study demonstrated that student performance was well-meaningly indicated by the congruence between the student and their professor's personality, and study hall atmosphere predicted the students' performance and satisfaction significantly. (Vandenberghe, 1999) further expanding research recreated the investigation of (Charles A. O'Reilly III, 1991) on the impact of level of congruity on the values of new employees and its inclinations on turnover and the organization's culture with the help of 630 sample of respondents of Belgium health-care industry. There results uncovered that those workers who during their early employment period have value profiles in line with their engaging organizations were bound to remain with the organization. Additionally, they also found that OCP (organizational culture profile) can be used in different nations with discrete cultural settings with the help of generalized structure of OCP (organizational culture profile).

(Michelle L Verquer, 2003) directed a metaanalytic survey of 21 researches conducted on the relations of person-organizational congruence with employee job satisfaction, organizational commitment and intent to turnover. The results of their investigation uncovered a significant relationship of person-organizational congruence employee job satisfaction, organizational commitment and employee turnover intentions. (Nazir, 2005) made an endeavor to investigate into person-culture congruence, socialization and worker's commitment relationship on employees of six banks two each from public and private sector and two overseas banks situated in the capital city of India Delhi by gathering data from two separate groups of employees with the assistance of three standard scales i.e. Socialization practices scale, organizational commitment scale and organizational culture profile by applying convenience sampling method. The results of the investigation demonstrate of having a remarkable relationship of person-culture congruence with commitment (normative) of employees of the banks scoring high on value congruence and socialization rehearses, and those banks scoring low on value congruence and socialization practices revealed insignificant relation of person-culture congruence with commitment (normative and affective). Accordingly, in the same year, (Eatin Yaniv, 2005) investigated a remarkable part of person-organizational congruence and presumed that person-organizational congruence has a noteworthy beneficial outcome upon the perception of workers toward brand values with regards to the values proclaimed by the management; eventually which in turn was found to affect clients' impression of brand values in a positive manner.

(J.Woehr, 2006) broadened the meta-analytic study of (Michelle L Verquer, 2003) by surveying the person-organizational congruence relationship with behavioural outcomes like, organizational citizenship behaviour, job performance and employee turnover. Findings of this study demonstrated a moderated relationship of person-organizational congruence in relation to several behavioural and attitudinal outcomes such as, job performance, organizational citizenship behaviour and employee turnover, employee performance. Notwithstanding to the above findings they also found congruence measurement (subjective congruence) were feebly related to behavioural outcomes. Whereas, congruence i.e., (perceived objective congruence) measures were moderately connected to behavioural and attitudinal outcomes. However, research in the wake of a quickly evolving conditions research have demonstrated that organizations need to take a gander at the idea of person-organizational congruence and should therefore plan their selection and socialization rehearses accordingly. In line with this, (Gupta, 2005) analyzed the person-organizational congruence and its relationship with organizational commitment, innovation and employee tenure by utilizing the data gathered from managers at manufacturing, an engineering and a construction organization. The aftereffects of the examination demonstrated that congruence of organizational values and person values likely increment the person's engrossment and attachment with the organization. Research has likewise been led to investigate the procedures through which various kinds of person-environment congruence identify with employees behaviours and attitude. (Martha C. Andrews, 2010) led an examination to investigate the ethical values of organization and its relation with personorganizational congruence and the consequences like employee work satisfaction and organizational commitment. The aftereffects of this examination revealed a significant positive relation of personorganizational congruence with the ethical values of organization and person-organizational congruence was emphatically identified with job satisfaction and organizational commitment.

Moreover, (Greguras, 2010) examined two contending models of person-organizational congruence where various sort of personenvironment congruence like (person-job congruence, person-organization congruence and person-group congruence) and its relationship with various individual and organizational outcomes like (worker's satisfaction, workers job performance and organizational commitment, organizational citizenship behaviour) was mediated or partially mediated by the satisfaction of psychological requirements for self-governance, relatedness and competence. Information from 164 all day working 
workers and their managers was gathered crosswise over three time frames. Results found that various psychological need satisfaction was predicted by various types of person-environemnet congruence and various workers outcomes were predicted with the satisfaction of various psychological needs. (Hamid, 2011) directed an examination to analyse the relationship of person-organizational congruence and person-job congruence with workers' engagement where the worker's engagement was found to have a positively noteworthy effect on the individual job performance, performance and success of an organization. This investigation concentrated on to know how the (KSAs) knowledge, skills and abilities of the worker's congruent to the job demands i.e. person-job congruence, person-organization congruence, that could be utilized in workers' engagement enhancement. For this purpose, they gathered data from engineers attached to seven (07) Malaysian semi-conductor companies. The aftermath of this examination uncovered critical constructive relationship workers' engagement with person-job congruence and person-organizational congruence. Furthermore, they recommended that workers who are in congruence with their organization and job, in term of their knowledge, skills and abilities (KSAs) might have an impact on workers work engagement that would be beneficial to the organization in turn.

Person-organizational congruence and its relationship with organizational commitment and Knowledge sharing behaviour of employees was analyzed by (Wajid A. Saleem, 2011) by utilizing information gathered from 315 scholarly supervisors of public division establishments of advanced education. The results illustrated a constructive and significant positive relationship of personorganizational congruence and organizational commitment along with the support for a relationship of person-organizational congruence with the knowledge sharing behaviour. In addition to the finding reported a negative relationship of personorganizational congruence with turnover intention. On the question of mediating role of employee engagement in relation to person-organizational congruence and employee turnover intentions (Mumtaz Ali Memon, 2014) carried out a study to examine to see the effect. The results of their study found a strong mediation of employee engagement in relation to person-organizational congruence and employee turnover intention, they also, argued that employee with higher level of engagement will tend to remain long with the organization and their tendency to leave the organization is very low. (Jongseok Cha, 2014) analyzed the relationship of prosocial identity (pro-social person-organizational congruence) with different employee outcomes of 589 hospital employees' including doctors, medical attendants, nurses and other staffs. The results of this investigation found a joint impact of personal and pro-social identity on the advancement of a feeling of organizational identification and on the pro-social attitudes toward associates, organization, and patients. In particular, pro-social personorganizational congruence had a relationship moving through a curved line with organizational identification, to such an extent that organizational identification expanded as organizational pro-social characteristics expanded toward personal pro-social identity and after that diminished when the organizational pro-social characteristics surpassed the personal pro-social identity. Moreover, organizational identification and pro-social behaviours expanded as both personal and organizational pro-social identity expanded from low to high. (Mahmut Demir, 2015 directed a study to dissect the relationship of person-organizational congruence in lodgings through organizational identification, work performance, abnormal production behaviour, and the intention to stay. To accomplish this study, an aggregate of 582 surveys were gathered from workers who were full-time workers of the five-star lodgings working inside the Mugla locale of Turkey. The result of this study identified and disclosed, that outer factors, like "person-organizational congruence", affect interior factors, like, "organizational identification", "work performance", "production abnormality" and the "intention to stay". Likewise, the results demonstrated that person-organizational congruence impacts organizational identification, work performance and intention to stay, while affects production abnormality behaviour. Additionally, the results show that the organizational identity affects work performance, intention to stay and production abnormality behaviour. Drawing upon the theory of conservation of assets (Pei Chen, 2016) examined the job stress role in relation to person-organizational congruence and job satisfaction by gathering data from 225 workers in 12 catering service organization in Beijing. Their study found new mechanism and the limit conditions between person-organizational congruence and job satisfaction. Additionally, job stress mediates the connections between personorganizational congruence and job satisfaction and supervisor support moderates the linkage of personorganizational congruence, work stress, and job satisfaction.

\section{CONCLUSIONS}

The ends got from this exploration are that person-organizational congruence decidedly influences the degree to which the employees' see their values are in harmony with those of the organization. The idea of person-organizational congruence like congruence between the values of a person and the organization, congruence of the individual goals and the organizational goals, congruence of the person's personality and the organizations personality by and large so far investigated either internal organizational aspects or 
external organizational aspects. As such, no study was found to the best of my knowledge that have explored this phenomenon simultaneously i.e. both internal and external organizational aspects. This paper has made a modest attempt in this direction to explore person-organizational congruence and its relationship with various individual and organizational outcomes, thus to include maximum number of organizational outcomes. Thusly, writing proposes that person-organizational congruence is an exceedingly persuasive variable, creating various constructive results for an organization. Be that as it may, person-organizational congruence and its connection with different organizational and individual level outcome variables like organizational commitment, workers' satisfaction, job performance, job execution, organizational citizenship behaviour and employee turnover are not only examined and are required to be investigated further reiterates the available literature. Moreover, one of the serious issues organizations face is a discrepancy among the worker's perception of values and the values possessed by the organizations. the problem is, in what manner can the organization minimize these discrepancies? The present study was a motivation in this direction to show that how can personorganizational congruence can play a lead role in delineating these discrepancies. It appears to be in this manner, that HR directors need to give due consideration to the domain of person-organizational congruence as a way to enhance the organizational performance and individual performance as well. However, a high person-organizational congruence may have likewise a pessimistic impact being an impediment to organizational change; a solid corporate culture, as an outcome of a good personorganizational congruence, may prompt a perilous firmness and powerlessness to see the earnestness for change.

\section{REFERENCES}

1. Anthony R. Wheeler, V. C. (2007). When person - organization (mis)fit and (dis)satisfaction lead to turnover: The moderating role of perceived job mobility. Journal of Managerial Psychology, Volume 22, Issue 2, Pages 203-219.

2. Charles A. O'Reilly III, J. C. (1991). People and organizational culture: A profile comparison approach to assessing person-organization fit. Academy of Management Journal, , Volume 34, Pages 487-516.

3. Chatman, J. A. (1989). Improving interactional organizational research: A model of personorganization fit. The Academy of Management Review, Volume 14, Issue 3, Pages 333-349.

4. Chatman, J. A. (1991). Matching people and organizations: Selection and socialization in public accounting firms. Administrative Science Quarterly, Volume 36, Pages 459-484.

5. David Dawley, M. C. (2010). Enhancing the ties that bind: mentoring as a moderator. Career
Development International, Volume 15, Issue 3, Pages 259-278.

6. David E. Bowen, G. E. (1991). Hiring for the organization not the job. Academy of Management Executive, Volume 5, Issue 4, Pages 35-51.

7. Eatin Yaniv, F. F. (2005). The impact of PersonOrganization fit on the Corporate Brand Perception of Employees and of Customers. journal of Change Management, Volume 5, Issue 4, Pages 447-461.

8. Greguras, G. J. (2010). Different Fits Satisfy Different Needs:Linking Person-Environment Fit to Employee Commitment and Performance Using Self-Determination Theory. Research Collection Lee Kong Chian School of Business, Paper 2559.

9. Gupta, R. T. (2005). Person-Organization Fit: Practices and Outcome. Indian Journal of Industrial Relations, Volume 41, Pages 64-78.

10. H. Kirk Downey, D. H. (1975). Congruence between Individual Needs, Organizational Climate, Job Satisfaction and Performance. The Academy of Management Journal, Volume 18, Issue. 1, Pages 149-155.

11. Hamid, S. N. (2011). . Relationship between person-job fit and person-organization fit on employees' work engagement: a study among engineers in semiconductor companies in Malaysia. Conference on Innovations in Business and Management.

12. J.Woehr, B. J. (2006). A quantitative review of the relationship between person-organization fit and behavioral outcomes. Journal of Vocational Behavior, Volume 63, Issue 3, Pages 389-399.

13. Johnson, A. L.-B. (2005). Consequences of individuals' fit at work: A meta-analysis of person-job, person-organization, person-group, and person- supervisor fit. Personnel Psychology, Volume 58, Pages 281-342.

14. Jongseok Cha, Y. K.-Y. (2014). personOrganization Fit on Prosocial Identity: Implications on Employee Outcomes. Journal of Business Ethics, Volume 123, Issue 1, Pages 5769.

15. Judge, R. D. (1992). The Relationship Between Person-Organization Fit and Career Success. Center for Advanced Human Resource Studies Cornell University.

16. KRISTOF, A. L. (1996). Person-organization fit: An integrative review of its conceptualizations, measurement, and implications. Personnel Psychology, Volume 49, Pages 1-50.

17. Mahmut Demir, S. S. (2015). The relationship between person-organization fit, organizational identification and work outcomes. Journal of Business Economics and Management, Volume 16, Issue 2.

18. Martha C. Andrews, T. B. (2011). Values and person-organization fit: Does moral intensity strengthen outcomes? Leadership \& Organization Development Journal.

19. Mehmet Sefa Ulutaş, A. K. (2011). The Effect Of Person-Organization Fit On Job Stress And Conflict: An Application On Employees Of Businesses In Dalaman International Airport . 
International Journal of Social Sciences and Humanity Studies, Volume 3, Issue 1, ISSN: 1309-8063.

20. Michelle L Verquer, T. A. (2003). A Metaanalysis of relations between personorganization fit and work attitudes. Journal of Vocational Behaviour, Volume 63, Pages 473489.

21. Mumtaz Ali Memon, R. S. (2014). PersonOrganization Fit and Turnover Intention: The Mediating Role of Employee Engagement. Global Business and Management Research: An International Journal, Volume 6, Issue 3.

22. Nazir, N. A. (2005). Person - Culture fit and Employee Commitment in Banks. . Vikalpa, Volume 30, Issue 3, Pages 39-51.

23. Pei Chen, P. S. (2016). The relationship between person-organization fit and job satisfaction. Journal of Managerial Psychology, ISSN: 02683946.

24. Samina Nawab, X. X. (2011). Person culture fit" as an approach for better adjustments of expatriates to new cultures: A case study of China. African Journal of Business Management, Volume 5, Issue 9, Pages 3429-3435.

25. Schaubroeck, J. G. (1998). Organization and occupation influences in the attraction-selectionattrition process. Journal of Applied Psychology, Volume 83, Issue 6, Pages 869-891.

26. Schneider, B. (1987). The people make the place. Personnel Psychology, , Volume 40, Issue 437453.

27. T., S. (2003). A contingency perspective on the importance of $P-J$ fit and $P-O$ fit in employee selection. Paper presented at the Annual Conference of Academy of Management.

28. Vandenberghe, C. (1999). Organizational culture, person-culture fit, and turnover: a replication in the health care industry. Journal of Organizational Behavior, Volume 20, Issue 2, Pages 175-184.

29. Vanka, J. W. (2005). A Cross-Cultural Empirical Analysis of Person-Organization Fit Measures as Predictors of Student Performance in Business Education: Comparing Students in the United States and India. Academy of Management Learning and Education, Volume 4, Issue 4, 409420.

30. Wajid A. Saleem, G. A. (2011). Person Organization fit, Organizational Commitment and Knowledge Sharing Attitude - An Analytical Study. . Information Management and Business Review, Volume 3,Issue 2, Pages 110-116. 